\title{
İlk Defa Sentezlenen Benzimidazol Türevlerinin Antioksidan Aktivitesinin İncelenmesi
}

\author{
Bahar BİLGIN SÖKMEN ${ }^{1 *}$, Tuğba SERTER ${ }^{1}$, Demet ÇAKIR ${ }^{1}$, Hakan BEKTAŞ ${ }^{1}$ \\ ${ }^{1}$ Giresun Üniversitesi, Fen Edebiyat Fakültesi, Kimya Bölümü, 28100, Giresun, TÜRKIYE
}

Geliş Tarihi: 31.05 .2017

*Sorumlu Yazar: bahar.sokmen@ giresun.edu.tr Kabul Tarihi: 30.10 .2017

\section{Özet}

Antioksidanlar, reaktif oksijen türlerinin oluşumunu ve bunların meydana getirdiği hasarı önlemek için vücutta bulunan savunma mekanizmalarıdır. Serbest radikalleri nötralize etmek için kullanılırlar. Antioksidan aktivitesinin varlığı, vücutta meydana gelebilecek çeşitli hastalıklara karşı savunma mekanizmasının var olduğunu göstermektedir. Bu çalışmada, ilk defa sentezlenen benzimidazol türevlerinin antioksidan aktiviteleri spektrofotometrik olarak incelendi. Benzimidazol türevlerinin antioksidan aktiviteleri, DPPH, ABTS radikal giderme aktivitesi ve indirgeme gücü gibi çeşitli antioksidan testleri ile tayin edildi. Elde edilen sonuçlar, BHT ve Troloks gibi sentetik antioksidanlarla karşılaștırıldı. Yapılan çalışmalar sonucunda benzimidazol bileşiklerinden özellikle 2, 5, 6a, $6 \mathbf{b}$ ve $7 \mathbf{b}$ nolu bileşiklerin antioksidan aktivite değerleri diğer bileşiklere oranla daha yüksek bulundu.

Anahtar Kelimeler: Benzimidazol Türevleri, Antioksidan Aktivite, DPPH Aktivitesi, ABTS Aktivitesi

\section{Investigating of the Antioxidant Activity of Firstly Synthesized Benzimidazole Derivatives}

\begin{abstract}
Antioxidant is a defence mechanism in thehuman body preventing the occurence of oxygen types and the damage generated by them. They are used for neutralizing free radicals. The presence of antioxidants activity indicates the presence of the defense mechanism against the various diseases in the human body. In this study, activities of for the first time synthesized benzimidazole compounds antioxidant activities are investigated spectrophotometrically. The antioxidant activities of benzimidazole derivatives were investigated by different antioxidant tests such as DPPH radical scavenging activity, ABTS radical scavenging activity and reducing power. All results were compared with synthetic antioxidants such as BHT and Trolox. As the result of the study, antioxidant activity level of the compounds especially $\mathbf{2 , 5 , 6 a , ~ 6 b}$ and $\mathbf{7 b}$ which are benzimidazole derivatives are found higher extent too there compounds.
\end{abstract}

Key Words: Benzimidazole Derivatives, Antioxidant, DPPH Activity, ABTS Activity. 


\section{Giriş}

Farmakolojik endüstride, fonksiyonel özellikteki değerli bileşiklerin hızlı ve ekonomik olarak sentezlenmesine ilişkin teknolojiye ilgi gittikçe artmaktadır. Bu bağlamda ilaç kimyası teknolojik ilerlemelerden son derece yararlanmaktadır. Günümüz dünyasının ölümcül hastalıklarının tedavisi için sayısız kemoterapik madde geliştirilmiş ve kullanılmış olmasına rağmen, tümör hücrelerine karşı gelişen direnç bu hücrelerin yok edilmesini zorlaştırmıştır. Bu sebeple çoğu zaman hastalığın tamamen ortadan kaldırılması mümkün olmamaktadır. Buna rağmen ilaca dayalı tedavi yaklaşımları, hala en çok uygulanan yöntemleri oluşturmaktadır. Bu kapsamda potansiyel biyolojik özellikte maddelerin sentezi için etkili yöntemlerin geliştirilmesi günümüzün önemli bir ilgi alanıdır (Foye, 1995).

Hızla gelişen ve durmaksızın ilerleyen teknoloji, çevre kirliliği, radyasyon, kontamine sular, tarım ilaçları, ağır metaller ve canlı hücrelerdeki oksijen metabolizması gibi birçok etken insan vücudunda kaçınılmaz olarak serbest radikallerin oluşumuna neden olmaktadırlar. Serbest radikaller, oksijenin oldukça reaktif formları olup, vücut hücrelerini tahrip etmektedir. Bu da kalp damar hastalıkları, kanser, katarakt, diyabet, karaciğer tahribatı ve diğer pek çok hastalığa davetiye çıkarmaktadır. Bu hastalıkların tedavisi, öncelikle serbest radikallerin olumsuz etkilerini bertaraf etmek ve hastalıkların oluşumunu engellemekle gerçekleşebilir (Kasnak ve Palamutoğlu, 2015.).

Antioksidanlar serbest radikallerin etkilerini yok edici sistemlerdir. Vücutta reaktif oksijen türleri (ROT)'nin oluşumunu ve bunların meydana getirdiği hasarı önlemek üzere enzimatik veya enzimatik olmayan birçok endojen antioksidan savunma mekanizması bulunmaktadır. Bunun yanında bazı ilaçlar, vitaminler ve sentetik gıda antioksidanları da ekzojen antioksidanlar olarak değerlendirilebilir (Blois, 1958).

Benzimidazol halkası üzerinde yapılan farklı sübstitüsyonlarla çok farklı farmakolojik etkiler ortaya çıkmakta olup bu durum araştırıcıların, her yıl artan oranlarda ilgisini çekmektedir. Bu ilginin nedeni, benzimidazol yapısının kimyasal olarak aktif olması ve türevlerinin farklı biyolojik etki göstermesidir. Bu farmakolojik aktiviteler arasında antihelmintik (Habernickel, 1992), antibakteriyel (Nofal ve ark., 2002), antiviral (Keurulainen ve ark., 2010), antifungal (Going ve Mayer, 1995), antihistaminik (Meanwell ve Krystal, 2007), antiprotozol (Kazimierczuk ve ark., 2002), antiülser (Patil ve ark, 2008), antikanser (Demirayak ve ark., 2011), antitüberküloz (Khairnar ve ark., 1981), antikonvülzan (antiepileptik) (Ramya ve ark., 2010), antidiyabetik (Hemalatha ve ark., 2006), antihipertansif (Kuba ve ark., 1993), antioksidan (Kuş ve ark., 2008), analzejik (Alagöz ve ark., 2004), anti-inflamatuar (Savall ve ark., 2010) ve tirozin kinaz inhibitörü (McBride ve ark., 2006) özellikleri sayılabilir. Ayrıca benzimidazol türevlerinin DNA yapısına bağlanma ilgisi 
oldukça yüksek olması, benzimidazollerin biyolojik aktivite göstermesine neden olmaktadır (Chakrabarty ve ark., 2006).

Bu çalışmada, ilk kez sentezlenen benzimidazol türevlerinin DPPH ve ABTS radikal giderme ve indirgeme gücü antioksidan aktiviteleri incelendi.

\section{Materyal ve Metot}

\subsection{Materyal}

\subsubsection{Kullanılan Kimyasallar}

Dipotasyum hidrojen fosfat, potasyum dihidrojen fosfat, metanol, etanol, potasyum ferrisiyanür, potasyum persülfat, triklorasetikasid (TCA), demir (III) klorür Merck (Darmstadt, Germany) firması; 1,1-difenil-2-pikrilhidrazil (DPPH), ABTS (2,2'-Azino-bis(3etilbenzenothiazoline-6-sülfonik asid), Trolox (6-hydroxy-2,5,7,8-tetramethyl chroman-2carboxylic acid), dimetilsülfoksit (DMSO), bütillenmiş hidroksi toluen (BHT) Sigma-Aldrich (Germany) firmasından sağlandı.

\subsubsection{Kullanılan Cihazlar}

Antioksidan aktivite absorbans ölçümlerinde Shimadzu UV Mini-1240 model UV-VIS Spektrofotometrede cihazı kullanıldı. pH metre Butech, hassas terazi Sartorius, manyetik karıştırıcı Chiltern Hotplate HS 31, vorteks Velp Scientifica, çalkalamalı su banyosu Memmert, santrifüj Kubota 4200, sonik su banyosu için ise Selectra marka cihazlar kullanıldı.

\subsection{Metot}

\subsubsection{Antioksidan Aktivite Yöntemleri}

Bu çalışma Giresun Üniversitesi Fen Edebiyat Fakültesi, Kimya Bölümü Organik Kimya Laboratuvarında Doç. Dr. Hakan BEKTAŞ tarafından sentezlenmiştir (Şekil 1). Benzimidazol türevlerinin uygun bir çözücü (Dimetil sülfoksit (DMSO), metanol, etanol, vs.) kullanılarak çözünmesi sağlandı. Çözünmüş haldeki türevler, yine aynı çözücü (DMSO) kullanılarak farklı konsantrasyonlara seyreltildi ve aşağıdaki çeşitli yöntemler kullanılarak antioksidan aktiviteleri spektrofotometrik olarak incelendi. 


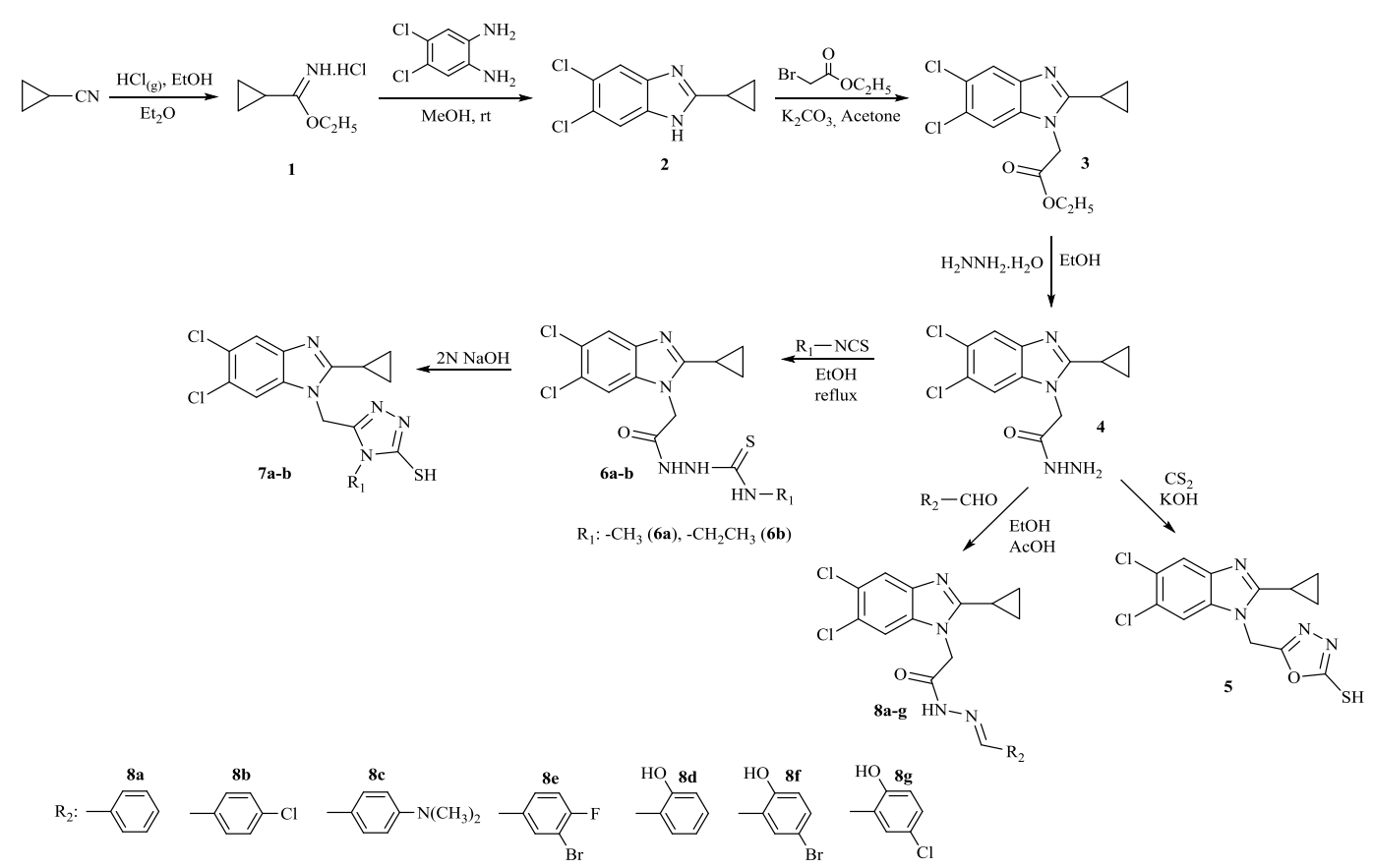

Şekil 1. Hedef Bileşiklerin Sentez Şeması (Menteşe ve ark., 2017)

\section{DPPH Radikal Giderme Aktivitesi Tayini}

20 mg/L DPPH, günlük olarak metanolde çözülerek hazırlandı. Bu çözeltiden 1,5 mL alınarak üzerine farklı konsantrasyonlarda hazırlanan benzimidazol türevlerinden $0,75 \mathrm{~mL}$ ilave edildi. 30 . dakikada 517 nm'de spektrofotometrede köre karşı absorbans değerleri ölçüldü. Kontrol çözeltisi olarak 0,75 mL metanol ve 1,5 mL DPPH çözeltisi kullanıldı. Kör olarak sadece metanol, standart olarak Trolox kullanıldı.

\section{Demir Indirgeme Gücü Tayini}

Benzimidazol türevlerinin indirgeme gücü tayini Oyaizu metoduna göre yapıldı (Oyaizu, 1986). Standart ve benzimidazol türevlerinden belli bir konsantrasyon aralığında çözeltiler hazırland1. Standart olarak BHT kullanıldı. Üzerine $\mathrm{pH}=6,6$ olan 0,2 M fosfat tamponundan 2,5 mL ilave edildi. Daha sonra \% 1'lik potasyum ferrisiyanür çözeltisinden 2,5 mL ilave edilerek karışım çalkalamalı su banyosunda $50{ }^{\circ} \mathrm{C}$ 'de 20 dakika inkübe edildi. Bu işlemden sonra reaksiyon karışımlarına 2,5 mL \% 10'luk TCA ilave edildi ve tüpler karıştırıldı. 3000 rpm'de 10 dakika santrifüj edildi. Süpernatandan $2,5 \mathrm{~mL}$ alınarak $2,5 \mathrm{~mL}$ destile su ve $0,5 \mathrm{~mL} \% 0,1$ 'lik demir (III) klorür ilave edildi ve 10 dakika bekletildi. Spektrofotometrede 700 nm'de köre karşı absorbans değerleri ölçüldü. Kör deney için $5 \mathrm{~mL}$ destile su alınarak, üzerine 2,5 mL demir (III) klorür çözeltisi ilave edildi.

Benzimidazol türevlerinin ve standartların indirgeyici güç eğrileri, konsantrasyon ve bu konsantrasyonlara karşı1ık gelen absorbanslar arasında çizildi. 


\section{ABTS Radikal Giderme Aktivitesi Tayini}

$1 \mathrm{~mL}$ destile suda 7,4 $\mathrm{mM}$ ABTS çözüldü, üzerine $2,6 \mathrm{mM}$ potasyum persülfattan $1 \mathrm{~mL}$ ilave edilerek karıştırıldı ve 12-16 saat karanlıkta bekletildikten sonra bu karışımın üzerine $60 \mathrm{~mL}$ metanol ilave edildi. Bu çözeltinin 734 nm'de spektrofotometrede metanole karşı absorbansı okundu. Her deney için bu karışım günlük olarak hazırlandı. Bu şekilde hazırlanan metanollü 2,850 mL ABTS çözeltisinin üzerine $150 \mu \mathrm{L}$ benzimidazol çözeltisi konuldu. 2 saat karanlıkta bekletilip spektrofotometrede 734 nm'de absorbans değerleri okundu. Standart olarak, Troloks kullanıldı. Kontrol olarak numune yerine metanol içeren reaksiyon karışımı kullanıldı (Arnao, 2000).

\section{Bulgular ve Tartışma}

$\mathrm{Bu}$ çalışmada ilk defa sentezlenen benzimidazol türevi bileşiklerin antioksidan aktiviteleri incelendi.

Benzimidazol türevi bileşiklerinin DPPH ve ABTS radikal giderme aktiviteleri, Tablo 1'de verildi. DPPH serbest radikal giderme aktivitesinin $\mathbf{6 b}\left(\mathrm{IC}_{50}=189,66 \pm 53,51 \mu \mathrm{M}\right)$ ve $7 \mathbf{b}\left(\mathrm{IC}_{50}=\right.$ $118,85 \pm 117,15 \mu \mathrm{M}$ ) bileşiklerinde en yüksek olduğu görüldü. ABTS radikal giderme aktivitesinin 6b $\left(\mathrm{IC}_{50}=186,37 \pm 1,32 \mu \mathrm{M}\right)$ ve $7 \mathbf{b}\left(\mathrm{IC}_{50}=124,22 \pm 39,07\right)$ bileşiklerinde en yüksek olduğu görüldü.

Tablo 1. Benzimidazol Türevi Bileşiklerin DPPH ve ABTS Radikal Giderme Aktiviteleri

\begin{tabular}{|c|c|c|}
\hline Bileşikler & $\begin{array}{c}\text { DPPH IC } 50 \\
(\mu \mathrm{M})^{*}\end{array}$ & $\begin{array}{c}\text { ABTS IC } 50 \\
(\mu \mathrm{M})^{*}\end{array}$ \\
\hline 2 & $4718,76 \pm 990,10$ & $1095,44 \pm 196,05$ \\
\hline 3 & $571,79 \pm 26,94$ & $269,10 \pm 22,01$ \\
\hline 4 & $814,85 \pm 57,06$ & $270,25 \pm 14,88$ \\
\hline 5 & $783,18 \pm 13,77$ & $270,25 \pm 14,88$ \\
\hline $6 a$ & $584,82 \pm 64,60$ & $216,43 \pm 5,93$ \\
\hline $6 b$ & $189,66 \pm 53,51$ & $186,37 \pm 1,32$ \\
\hline $7 \mathrm{a}$ & $2218,62 \pm 118,39$ & $286,71 \pm 17,23$ \\
\hline $7 \mathrm{~b}$ & $197,41 \pm 6,04$ & $124,22 \pm 39,07$ \\
\hline $8 \mathrm{a}$ & $2527,59 \pm 590,60$ & $467,58 \pm 36,48$ \\
\hline $8 b$ & $6619,78 \pm 23,35$ & $1851,27 \pm 234,95$ \\
\hline $8 \mathrm{c}$ & $831,61 \pm 16,51$ & $490,41 \pm 1,40$ \\
\hline $8 d$ & $3700,84 \pm 407,71$ & $989,53 \pm 295,227$ \\
\hline $8 \mathrm{e}$ & $1973,67 \pm 532,99$ & $285,96 \pm 3,99$ \\
\hline $8 \mathrm{f}$ & $3014,80 \pm 965,31$ & $490,41 \pm 1,40$ \\
\hline $8 g$ & $2362,13 \pm 927,58$ & $375,58 \pm 6,54$ \\
\hline Trolox & $132,03 \pm 9,75$ & $214,55 \pm 24,56$ \\
\hline Rutin & $44,11 \pm 1,59$ & $52,42 \pm 2,01$ \\
\hline
\end{tabular}

* Standart sapma. 
Benzimidazol bileşiklerinin demir indirgeme gücü konsantrasyona karş1 absorbans tablosu olarak değerlendirildi ve BHT ile aktiviteleri karşılaştırıldı. Bu değerler Tablo 2.'de verildi. Demir indirgeme gücü radikal giderme aktivitesinin 6a $(200 \mu \mathrm{g} / \mathrm{mL}$ konsantrasyondaki absorbans değeri $0,19 \pm 0,004)$ ve $7 \mathbf{b}(200 \mu \mathrm{g} / \mathrm{mL}$ konsantrasyondaki absorbans değeri $0,47 \pm 0,024)$ bileşiklerinde en yüksek olduğu görüldü. Benzimidazol konsantrasyonu arttıkça indirgeme gücü de artmaktadır.

Tablo 2. Benzimidazol Türevi Bileşiklerin İndirgeme Gücü Aktiviteleri

\begin{tabular}{|c|c|c|c|c|}
\hline Bileşikler & $\begin{array}{c}\text { Konsantrasyon } \\
(\mu \mathrm{g} / \mathrm{mL})\end{array}$ & $\begin{array}{c}\text { İndirgeme Gücü } \\
\text { Absorbans } \\
\text { Değerleri* }\end{array}$ & Bileşikler & $\begin{array}{c}\text { İndirgeme Gücü } \\
\text { Absorbans } \\
\text { Değerleri* }\end{array}$ \\
\hline 2 & $\begin{array}{c}50 \\
100 \\
150 \\
200\end{array}$ & $\begin{array}{c}0,02 \pm 0,004 \\
0,03 \pm 0,007 \\
0,05 \pm 0,004 \\
0,07 \pm 0,0007\end{array}$ & $6 a$ & $\begin{array}{l}0,14 \pm 0,002 \\
0,15 \pm 0,004 \\
0,16 \pm 0,010 \\
0,19 \pm 0,004\end{array}$ \\
\hline 3 & $\begin{array}{c}50 \\
100 \\
150 \\
200 \\
\end{array}$ & $\begin{array}{l}0,06 \pm 0,002 \\
0,08 \pm 0,004 \\
0,10 \pm 0,006 \\
0,13 \pm 0,009 \\
\end{array}$ & $7 b$ & $\begin{array}{l}0,19 \pm 0,031 \\
0,28 \pm 0,012 \\
0,31 \pm 0,014 \\
0,47 \pm 0,024\end{array}$ \\
\hline 4 & $\begin{array}{c}50 \\
100 \\
150 \\
200\end{array}$ & $\begin{array}{l}0,08 \pm 0,003 \\
0,13 \pm 0,006 \\
0,14 \pm 0,010 \\
0,19 \pm 0,001\end{array}$ & $7 \mathrm{a}$ & $\begin{array}{l}0,04 \pm 0,008 \\
0,08 \pm 0,005 \\
0,12 \pm 0,001 \\
0,14 \pm 0,008\end{array}$ \\
\hline 5 & $\begin{array}{c}50 \\
100 \\
150 \\
200 \\
\end{array}$ & $\begin{array}{l}0,07 \pm 0,004 \\
0,08 \pm 0,006 \\
0,11 \pm 0,016 \\
0,17 \pm 0,012\end{array}$ & $6 b$ & $\begin{array}{l}0,07 \pm 0,002 \\
0,08 \pm 0,004 \\
0,12 \pm 0,008 \\
0,14 \pm 0,006\end{array}$ \\
\hline $8 a$ & $\begin{array}{c}50 \\
100 \\
150 \\
200\end{array}$ & $\begin{array}{l}0,03 \pm 0,009 \\
0,05 \pm 0,006 \\
0,07 \pm 0,006 \\
0,11 \pm 0,005\end{array}$ & $8 d$ & $\begin{array}{l}0,03 \pm 0,005 \\
0,04 \pm 0,004 \\
0,06 \pm 0,003 \\
0,07 \pm 0,001\end{array}$ \\
\hline $8 b$ & $\begin{array}{c}50 \\
100 \\
150 \\
200\end{array}$ & $\begin{array}{c}0,02 \pm 0,004 \\
0,04 \pm 0,004 \\
0,05 \pm 0,007 \\
0,06 \pm 0,0007\end{array}$ & $8 \mathrm{f}$ & $\begin{array}{l}0,04 \pm 0,003 \\
0,05 \pm 0,007 \\
0,07 \pm 0,010 \\
0,09 \pm 0,006\end{array}$ \\
\hline $8 \mathrm{c}$ & $\begin{array}{c}50 \\
100 \\
150 \\
200 \\
\end{array}$ & $\begin{array}{l}0,04 \pm 0,011 \\
0,05 \pm 0,007 \\
0,07 \pm 0,008 \\
0,08 \pm 0,002\end{array}$ & $8 g$ & $\begin{array}{l}0,05 \pm 0,002 \\
0,07 \pm 0,009 \\
0,10 \pm 0,006 \\
0,12 \pm 0,004\end{array}$ \\
\hline $8 \mathrm{e}$ & $\begin{array}{c}50 \\
100 \\
150 \\
200\end{array}$ & $\begin{array}{l}0,08 \pm 0,004 \\
0,09 \pm 0,009 \\
0,11 \pm 0,013 \\
0,16 \pm 0,009\end{array}$ & BHT & $\begin{array}{c}0,16 \pm 0,01 \\
0,21 \pm 0,02 \\
0,27 \pm 0,02 \\
0,31 \pm 0,03\end{array}$ \\
\hline
\end{tabular}

*Standart sapma

DPPH radikali, kararlı diyamagnetik molekül haline gelmek için bir elektron veya hidrojen radikali alan serbest bir radikaldir (Soares ve ark., 1997). Sebest radikaller lipid peroksidasyonda yer alırlar ve birçok kronik hastalıkta önemli rol alırlar (Halliwell ve Gutteridge, 1989). Bundan dolayı serbest radikalleri temizleme gücü önemli bir antioksidan özelliktir. Çalışılan benzimidazol bileşiklerinde DPPH oranı en yüksek 5 ve $6 \mathbf{a}$ bileşiklerinde tespit edildi. 
İndirgeyici güç, bitkinin potansiyel antioksidan aktivitesinin önemli bir göstergesidir. Ayrıca benzimidazol konsantrasyonu arttıkça indirgeyici güç aktivitesinde de artış gözlendi. Bu çalışmada, benzimidazol bileşiklerinden indirgeme gücünün en fazla olan 6a ve $7 \mathbf{b}$ nolu bileşiklerin sahip olduğu bulundu.

DPPH serbest radikali, doğal bileşiklerin serbest radikal süpürme aktivitesini belirlemek için kullanılmasına karşın; ABTS serbest radikali, genellikle çözünürlük ve girişim sorunu ortaya çıktığında ve DPPH temelli tayinler yeterli gelmediği zaman kullanılır (Osman ve ark., 2006). Bu çalışmada, ABTS radikal giderme aktivitesi en yüksek $\mathbf{2}$ ve $\mathbf{6 b}$ bileşiklerinde görüldü.

Kerimov ve arkadaşları tarafından yapılan çalışmada; imidazol bileşiklerinin antioksidan aktiviteleri DPPH radikali süpürücü aktivitesi incelenmiş ve bileşiklerin her iki aktivite açısndan orta derecede aktivite gösterdikleri izlenmiştir. 2-[(2-(4-Klorofenil)-1H-benzo[d]imidazol-1il)metil]-5-(4-florofenil)-1,3,4-oksadiazol bileşiğinin ise incelenen imidazol bileşikleri arasında en aktif bileşik olduğu bulunmuştur (Kerimov ve ark., 2011).

Eş tarafından yapılan çalışmada; triazol türevlerinin antioksidan aktiviteleri (DPPH ve ABTS radikal giderme ve indirgeme gücü) incelenmiş ve bileşiklerin orta düzeyde antioksidan aktivite gösterdiği (ABTS için IC50= 6480,25 $\pm 65,13 \mu \mathrm{M}$ ) bildirilmektedir (Eş, 2013).

Baltaş ve arkadaşları tarafından yapılan çalışmada; farklı tür heterosiklik halkalar içeren, bazı benzimidazol türevi bileşiklerin, antioksidan radikal süpürme aktiviteleri (ABTS, DPPH), incelenmiş olup bileşiklerden bazılarının ABTS metoduna göre çok iyi radikal süpürme aktivitesi sergilediği bildirilmektedir (Baltaş ve ark. 2015).

Yapılan bu çalışmada ise; ilk defa sentezlenmiş 15 adet benzimidazol bileşiğinin antioksidan aktiviteleri; DPPH radikal giderici aktivite, demir indirgeme gücü ve ABTS radikal giderici aktivite gibi çeşitli antioksidan testler kullanılarak incelendi. Elde edilen sonuçlar, BHT ve Troloks gibi standart antioksidanlar ile karşılaştırılarak değerlendirildi. Benzimidazol bileşiklerinin her üç aktivite açısından orta derecede etki gösterdikleri belirlendi. Ancak incelenen bileşikler arasında 2, $\mathbf{5}, \mathbf{6 a}, \mathbf{6 b}$ ve $\mathbf{7 b}$ bileşiklerinin en aktif bileşikler oldukları saptandı.

\section{Sonuçlar ve Öneriler}

Hızla gelişen ve durmaksızın ilerleyen teknoloji, çevre kirliliği, radyasyon, kontamine sular, tarım ilaçları, ağır metaller ve canlı hücrelerdeki oksijen metabolizması gibi birçok etken insan vücudunda kaçınılmaz olarak serbest radikallerin oluşumuna neden olmaktadırlar. Serbest radikaller, oksijenin oldukça reaktif formları olup, vücut hücrelerini tahrip etmektedir. Bu da kalp damar hastalıkları, kanser, katarakt, diyabet, karaciğer tahribatı ve diğer pek çok hastalığa davetiye çıkarmaktadır. Bu hastalıklara çözüm getirmek öncelikle serbest radikallerin olumsuz etkilerini 
bertaraf etmek ve hastalıkların oluşumunu engellemekle gerçekleşebilir (Kasnak ve Palamutoğlu, 2015).

Antioksidanlar serbest radikallerin etkilerini yok edici sistemlerdir. Vücutta ROT'ların oluşumunu ve bunların meydana getirdiği hasarı önlemek üzere enzimatik veya enzimatik olmayan birçok endojen antioksidan savunma mekanizması bulunmaktadır. Bunun yanında bazı ilaçlar, vitaminler ve sentetik gıda antioksidanları da ekzojen antioksidanlar olarak değerlendirilebilir (Blois, 1958).

İnsan ve veteriner ilaçlarının yapımında antihelmintik olarak kullanılan benzimidazol önemli bir heterosiklik bileşiktir. Benzimidazol türevlerinin DNA yapısına bağlanma ilgisi oldukça yüksektir. $\mathrm{Bu}$ özellik, benzimidazollerin biyolojik aktivite göstermesine neden olmaktadır (Chakrabarty, 2006).

Sonuç olarak, bu çalışmada ilk defa sentezlenmiş benzimidazol bileşiklerinin bütün testlerde antioksidan aktivite gösterdiği ve iyi bir antioksidan kaynağı olabileceği ve literatüre önemli bir katkı sağlandığ1 görüşüne varılmıştır.

\section{Teşekkür}

Bu çalışmayı FEN-BAP-C-200515-10 numaralı proje ile destekleyen Giresun Üniversitesi Bilimsel Araştırma Projeleri (BAP) Koordinasyon Birimine teşekkürlerimi sunarım.

\section{Kaynaklar}

Alagöz, Z.G., Can-Eke, B., Coban, T., Iscan, M., Büyükbingöl, E. (2004). Antioxidant properties of novel benzimidazole petinoids. Archives of Pharmaceutical Pharma Medicinal Chemistry. 337: 188-192.

Arnao, M.B., (2000). Some methodological problems in the determination of antioxidant activity using chromogen radicals. A practical case. Trends in Food Science and Technology. 11: 419-421.

Baltaş, N., Menteşe, E., Pakyıldız, S., Yılmaz, F. (2015, Mart). Yeni benzimidazol türevi bileşiklerin sentezi, antioksidan özellikleri ve klinik öneme sahip bazı enzimler üzerine inhibisyon etkilerinin incelenmesi. 3.Illaç Kimyası: Illaç Etkin Maddesi Tasarımı, Sentezi, Üretimi ve Standardizasyonu Kongresi, RizeTURKEY.

Blois, M. S. (1958). Antioxidant determinations by the use of a stable free radical. Nature, 26: 1119-1200.

Brand-Williams, W., Cuvelier, M.E., Berset, C. (1995). Use of a free radical method to evaluate antioxidant acitivity, Lebensmittel-Wissenschaft und-Technologie/Food Science and Technolog, 28: 25-30.

Chakrabarty, M., Karmakar, S., Mukherji, A., Arima, S., Harigaya, Y. (2006). Application of sulfamic acid as an eco-friendly catalyst in an expedient synthesis of benzimidazoles. Heterocycles. 68: 967-974.

Eş, S. (2013).̇̇lk defa sentezlenen 1,2,4-triazol schiff bazı bileşiklerininantioksidan, anti-elastaz ve antitirozinaz aktivitelerinin incelenmesi. Giresun Üniversitesi, Fen Bilimleri Enstitüsü, Yüksek Lisans Tezi, pp. 92, Giresun.

Foye, W.O. (1995). Cancer Chemotherapeutic Agents. American Chemical Society. 1-212.

Demirayak, S., Kayagil, I., Yurttas, L. (2011). Microwave supported synthesis of some novel 1,3diarylpyrazino[1,2-a]benzimidazol derivatives and investigation of their anticancer activities. European Journal of Medicinal Chemistry, 46 (1): 411-416.

Going, C.J., Mayer, V.W. (1995). Induction of chromosome loss in saccharomyces cerevisiae strain D61.M by selected benzimidazole compounds. Mutation Research. 343: 185-199. 
Habernickel, V.J. (1992). Alkyl-5-heterocyclic-benzimidazolyl-carbamate derivatives. Drugs made in Germany, 35: 97.

Hemalatha, S., Ayyappan, T., Shanmugam, S., Nagavalli, S., Kurubha, T.S. (2006). evaluation of antidiabetic and diuretic activity of polyherbal formulation. Indian Journal of Trade Knowledge. 5: 468-470.

Kasnak, C., Palamutoğlu, R. (2015). Doğal antioksidanların sınıflandırılması ve insan sağlığına etkileri. Türk Tarım - Gida Bilim ve Teknoloji Dergisi, 3: 226-234.

Kazimierczuk, Z., Upcroft, J.A., Upcroft, P., Gorska, A., Starosciak, B., Agnieszka, L. (2002). Synthesis, Antiprotozoal and Antibacterial Activity of Nitro- and Halogeno-Substituted Benzimidazole Derivatives. Acta Biochimica Polonica, 49: 185-195.

Kerimov, İ. (2011). Bazı yeni oksadiazol benzimidazol türevlerinin sentezi yapılarının aydınlatılması ve antioksidan aktivitelerininin değerlendirilmesi. Ankara Üniversitesi, Sağllk Bilimleri Enstitüsü, Doktora Tezi, pp. 143, Ankara.

Keurulainen, L., Salin, O., Siiskonen, A., Kern, J. M., Alvesalo, J., Kiuru, P. and Maass, M. (2010). Design and synthesis of 2-arylbenzimidazoles and evaluation of their inhibitory effect against Chlamydia pneumoniae. Journal of Medicinal Chemistry. 53: 7664-7674.

Khairnar, V.L., Lokhande, S.R., Khadse, B.G. (1981). Synthesis and antifungal and anti tubercular properties of some benzimidazole derivatives, Chemical Abstract. 95: 203833h.

Kuba, K., Kohara, Y., Imamiya, E., Sugiura, Y., Inada, Y., Furukawa, Y., Nishikawa, K., Naka, T. (1993). Nonpeptide angiotensin-I receptor antagonists. synthesis and biological activity of benzimidazoles. Journal of Medicinal Chemistry, 36: 2182-2195.

Kuş, C., Ayhan, K.G., Ozbey, S., Kaynak, F.B., Kaya, M., Coban, T., Can, E.B. (2008). Synthesis and antioxidant properties of novel n-methyl-1,3,4-thiadiazole-2-amino and 4-methyl-2h-1,2,4-triazole3(4h)-thione derivatives of benzimidazole class. Bioorganic and Medicinal Chemistry, 16: 4294-4303.

McBride, C. M., Renhowe, P. A., Heise, C., Jansen, J. M., Lapointe, G., Ma, S., Pineda, R., Vora, J., Wiesmann, M., Shafer, C.M. (2006). Design and Structure. Bioorganic \& Medicinal Chemistry Letters, 16: 3595-3599.

Meanwell, N.A., Krystal, M. (2007). Respiratory syncytial virus: the discovery and optimization of orally bioavailable fusion inhibitors. Drugs Future, 32: 441-445.

Menteşe, E., Bektaş, H., Bilgin Sokmen, B., Emirik, M., Çakır, D., Kahveci, B. (2017). Synthesis and molecular docking study of some 5,6-dichloro-2-cyclopropyl-1 $h$-benzimidazole derivatives bearing triazole, oxadiazole, and imine functionalities as potent inhibitors of urease. Bioorganic \& Medicinal Chemistry Letters. 27, 3014-3018.

Nofal, Z.M., Fahmy, H.H. Mohamed, H.S. (2002). Synthesis, antimicrobial and molluscicidal activities of new benzimidazole derivatives. Archives of Pharmacal Research Journal. 25: 28-38.

Osman, A.M., Wong, K.K.Y., Fernyhough, A. (2006). ABTS radical driven-oxidation of polyphenols: Isolation and elucidation of covalent adducts, Biochemical and Biophysical Research Communications. 346: 321-329.

Oyaizu, M. (1986). Studies on products of browning reaction: antioxidative activities of products of browning reaction prepared from glucosamine. Japanese Journal of Nutrition. 44: 307-315.

Patil, A., Ganguly, S., Surana, S. (2008). A Systematic Review of benzimidazole derivatives as an antiulser agent. Rasayan Journal of Chemistry. 1 (3): 447-460.

Ramya, V.S., Kallappa, M.H., Keri, S. (2010). Derivatives of benzimidazole pharmacophore: synthesis anticonvulsant. European Journal of Medicinal Chemistry. 45: 1753-1759.

Savall, B.M., Edwards, J.P., Venable, J.D., Buzard, D.J., Thurmond, R., Hack, M., McGovern, P. (2010). Agonist/antagonist modulation in a series of 2-aryl benzimidazole $\mathrm{h}_{4}$ receptor ligands. Bioorganic \& Medicinal Chemistry Letters, 20: 3367-3371.

Soares, J.R., Dinis, T.C.P., Cunha, A.P., Almeida, L.M. (1997). Antioxidant activity of some extracts of Thymus zygis. Free Radical Research. 26: 469-478. 